\title{
Analysis of the accuracy and precision of the McMaster method in detection of the eggs of Toxocara and Trichuris species (Nematoda) in dog faeces
}

\author{
Maciej Kochanowski ${ }^{1}$, Joanna Dąbrowska ${ }^{1}$, Jacek Karamon $^{1}$, Tomasz Cencek ${ }^{1}$ and Zbigniew Osiński ${ }^{2}$ \\ ${ }^{1}$ Department of Parasitology and Invasive Diseases, National Veterinary Research Institute in Pulawy, Pulawy, Poland; \\ ${ }^{2}$ Department of Hygiene of Animal Feedingstuffs, National Veterinary Research Institute in Pulawy, Pulawy, Poland
}

\begin{abstract}
The aim of this study was to determine the accuracy and precision of McMaster method with Raynaud's modification in the detection of the eggs of the nematodes Toxocara canis (Werner, 1782) and Trichuris ovis (Abildgaard, 1795) in faeces of dogs. Four variants of McMaster method were used for counting: in one grid, two grids, the whole McMaster chamber and flotation in the tube. One hundred sixty samples were prepared from dog faeces (20 repetitions for each egg quantity) containing $15,25,50$, 100, 150, 200, 250 and 300 eggs of T. canis and T. ovis in $1 \mathrm{~g}$ of faeces. To compare the influence of kind of faeces on the results, samples of dog faeces were enriched at the same levels with the eggs of another nematode, Ascaris suum Goeze, 1782. In addition, 160 samples of pig faeces were prepared and enriched only with $A$. suum eggs in the same way. The highest limit of detection (the lowest level of eggs that were detected in at least $50 \%$ of repetitions) in all McMaster chamber variants were obtained for $T$. canis eggs (25-250 eggs/g faeces). In the variant with flotation in the tube, the highest limit of detection was obtained for T. ovis eggs (100 eggs/g). The best results of the limit of detection, sensitivity and the lowest coefficients of variation were obtained with the use of the whole McMaster chamber variant. There was no significant impact of properties of faeces on the obtained results. Multiplication factors for the whole chamber were calculated on the basis of the transformed equation of the regression line, illustrating the relationship between the number of detected eggs and that of the eggs added to the sample. Multiplication factors calculated for T. canis and T. ovis eggs were higher than those expected using McMaster method with Raynaud modification.
\end{abstract}

Keywords: validation, quantitative coproscopy, diagnostics, carnivores

Carnivores (especially dogs, cats and foxes) may serve as hosts of important zoonotic intestinal parasites, including nematodes. Therefore, faeces of carnivores containing eggs of these parasites represent a potential source of human infection. As a result, faecal samples from carnivores are frequently examined for the presence of nematode eggs using different modifications of a quantitative McMaster method (Gordon and Whitlock 1939).

In the senior author's laboratory, McMaster method with Raynaud's modification (Raynaud 1970) has been used for long time and various reactions of different types of parasite eggs during flotation in the McMaster chamber and in the tube have been observed. Moreover, specific properties of faecal samples of different animal species, including carnivores, appeared to influence significantly obtained results.

Currently, multiplication factors are used, representing the proportion of the sample dilution ratio and the volume of individual part of the McMaster chamber, but these multiplication factors do not allow for the correct estimation of the number of parasites in sample (Kochanowski et al. 2012). Therefore, quantitative estimation of the number of eggs in gram of faeces in McMaster method with Raynaud's modification by using universal multiplication factors for different types of parasite eggs needs verification.

It is worth mentioning that most papers on McMaster method and its modifications were based on examinations carried out with faeces of animals naturally or experimentally infected, in which real numbers of parasite eggs in samples were not known (Ward et al. 1997, Ojeda-Robertos et al. 2007, Pereckiene et al. 2007, Daş et al. 2011). Most authors confined their analysis only to comparison of different methods without estimation of the real accuracy and precision of detection of parasitic developmental stages (Rossangio and Gruner 1991, Turkson and Ahafia 1994, Levecke et al. 2009).

The aim of this study was to determine the accuracy and precision of McMaster method with Raynaud's modification (Raynaud 1970) in the detection of eggs of parasitic nematodes of the genera Toxocara Stiles, 1905 and Trichuris Roederer, 1761 in faeces of carnivores with the use of samples enriched with known numbers of eggs. 


\section{MATERIALS AND METHODS}

\section{Parasite eggs and faeces}

Experiment was carried out with faeces of dogs and pigs characterized by solid consistence. Faeces were free of parasite eggs, which was confirmed by double examination by flotation according to Fülleborn (1921), and faecal samples weighting $2 \mathrm{~g}$ were used. The samples were enriched by eggs of the nematodes Toxocara canis (Werner, 1782), Trichuris ovis (Abildgaard, 1795) and Ascaris suum Goeze, 1782. The eggs of T. canis were isolated from females defecated by naturally-infected dogs, those of $T$. ovis were obtained from females isolated from the caecum of experimentally infected mice, and the eggs of A. suum were obtained from females found in the intestines of slaughtered pigs.

After isolation the eggs were suspended in physiological solution (saline; $0.9 \% \mathrm{NaCl}$ ) and stored in $4{ }^{\circ} \mathrm{C}$ until their use. Then, the eggs placed in a small drop (about $0.1 \mathrm{ml}$ volume) of saline on a slide. Doses of parasite eggs to enrich samples were prepared by counting eggs individually for each sample. Thereafter, the eggs were rinsed from slides to faecal samples with flotation solution. The volume of flotation solution used to rinse parasite eggs was subtracted from the total volume, i.e. $28 \mathrm{ml}$ of flotation solution, which was used for examination of samples (see below). Then, the slide was again examined to ensure that all eggs were removed. One hundred and sixty doses of eggs of T. canis, T. ovis and A. suum were added to the samples of $\operatorname{dog}$ faeces and 160 doses of the eggs of $A$. suum were added to the samples of pig faeces.

\section{McMaster method with Raynaud's modification}

The experiments were carried out according to McMaster method with Raynaud's modification. McMaster chambers produced by the Research Institute of Organic Agriculture (FiBL, Frick, Switzerland) were used. The volume of the whole chamber was $1.5 \mathrm{ml}$, the size of one grid $10 \mathrm{~mm} \times 10 \mathrm{~mm}$ and that of half of the chamber $24 \mathrm{~mm} \times 21 \mathrm{~mm}$ (Fig. 1). The volume of a tube, used additionally according to this modification, was $14 \mathrm{ml}$. Twenty eight $\mathrm{ml}$ of saturated solution of magnesium sulfate $\left(\mathrm{MgSO}_{4}\right)$ were added to $2 \mathrm{~g}$ sample of faeces. The McMaster chamber or flotation tube was filled with obtained suspension (in the case of the tube the convex meniscus was obtained and a cover slip was placed on the top of the tube). Samples were examined microscopically after $3 \mathrm{~min}$ in the McMaster chamber and after $20 \mathrm{~min}$ in the tube. Eggs were then counted at $100 \times$ magnification in different parts of the McMaster chamber: in one grid, two grids, the whole McMaster chamber and flotation slide (variant in the tube)

\section{Sample examination}

One hundred and sixty enriched samples of dog faeces (20 repetitions for each eggs level) containing 15, 25, 50, $100,150,200,250$ and 300 eggs of three species of nematodes (T. canis, T. ovis and A. suum) per $1 \mathrm{~g}$ of faeces were

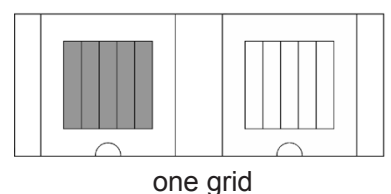

one grid

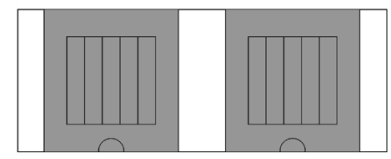

whole chamber

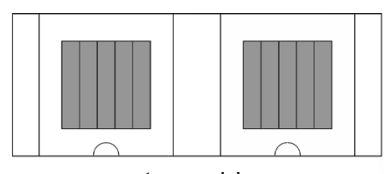

two grids

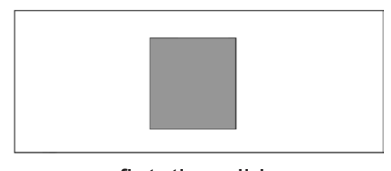

flotation slide
Fig. 1. Four variants of counting in McMaster chamber and flotation slide used in the investigation (gray colour shows the counting area).

prepared; eggs of A. suum served as a control to show the influence of properties of faeces on the results. Samples were examined using McMaster method with Raynaud's modification. To compare the influence of kind of faeces on the efficiency of the method, 160 pig faecal samples were prepared and enriched with $A$. suum eggs in the same way. To determine reproducibility, 20 additional samples of dog faeces containing 100 eggs of $T$. canis and T. ovis per $1 \mathrm{~g}$ faeces were prepared. These samples were examined in the same way as in the main experiment, but by different persons.

\section{Statistical analysis}

The results were analyzed separately for each variant of counting: one grid, two grids, whole McMaster chamber and flotation slide. Normality of distribution of data was tested by Shapiro-Wilk test $(\mathrm{P}<0.05)$. If the normality of distribution was not confirmed, results were transformed to normal distribution using the natural logarithm (ln) of the number of detected parasite eggs +1 (Utzinger et al. 2008). Additionally, Poisson distribution of data was tested by Kolmogorov-Smirnov test $(\mathrm{P}<0.05)$. For each of eight levels $(15,25,50,100,150,200,250$ and 300 eggs per $1 \mathrm{~g}$ of faeces) consisting of 20 repetitions (separately for $T$. canis, $T$. ovis and A. suum eggs added to the dog faeces and $A$. suum added to pig faeces), mean values of detected eggs, $95 \%$ confidence intervals for means, standard deviations and coefficients of variation were calculated. Limit of detection was calculated as the lowest level of eggs, which were detected in at least $50 \%$ of repetition (Lombard 2006).

The sensitivity of the method was calculated as ratio of the number of samples that were identified as positive to all checked samples in examination (to guarantee the calculation of the sensitivity in the diagnostic range of the method, only samples with the number of eggs above the limit of detection were taken into account; see ISO 16140:2003). In order to calculate the multiplication factors for estimation of a real number of eggs in $1 \mathrm{~g}$ of faeces, the regression line and the equation $y=a x+b$ illustrating the relation of number of eggs found (y) to the number of eggs added to the sample (x) were determined. Mul- 
Table 1. Parameters describing accuracy and precision for individual contents of the eggs of Toxocara canis and Trichuris ovis (15-300 eggs/g) in all variants of McMaster method with Raynaud's modification.

\begin{tabular}{|c|c|c|c|c|c|c|c|c|c|}
\hline & & \multicolumn{4}{|c|}{ Toxocara canis } & \multicolumn{4}{|c|}{ Trichuris ovis } \\
\hline & & one grid & two grids & $\begin{array}{l}\text { whole } \\
\text { chamber }\end{array}$ & $\begin{array}{l}\text { flotation } \\
\text { slide }\end{array}$ & one grid & two grids & $\begin{array}{l}\text { whole } \\
\text { chamber }\end{array}$ & $\begin{array}{l}\text { flotation } \\
\text { slide }\end{array}$ \\
\hline \multirow{5}{*}{15} & mean $\ln$ & 0.07 & 0.16 & 0.25 & 0.16 & 0.21 & 0.37 & 0.72 & 0.35 \\
\hline & $\mathrm{SD} \ln$ & 0.21 & 0.34 & 0.40 & 0.40 & 0.39 & 0.50 & 0.52 & 0.42 \\
\hline & CV\% ln & $308 \%$ & $211 \%$ & $163 \%$ & $254 \%$ & $184 \%$ & $133 \%$ & $73 \%$ & $118 \%$ \\
\hline & mean anti-ln & 1.07 & 1.17 & 1.28 & 1.17 & 1.24 & 1.45 & 2.05 & 1.42 \\
\hline & $95 \% \mathrm{CI}$ & $0.70-1.64$ & $0.60-2.29$ & $0.57-2.88$ & $0.52-2.63$ & $0.56-2.72$ & $0.54-3.92$ & $0.72-5.80$ & $0.62-3.27$ \\
\hline \multirow{5}{*}{25} & mean $\ln$ & 0.14 & 0.21 & 0.44 & 0.52 & 0.30 & 0.44 & 0.83 & 0.40 \\
\hline & $\mathrm{SD} \ln$ & 0.28 & 0.33 & 0.43 & 0.56 & 0.44 & 0.54 & 0.57 & 0.38 \\
\hline & $\mathrm{CV} \% \ln$ & $205 \%$ & $157 \%$ & $98 \%$ & $106 \%$ & $145 \%$ & $124 \%$ & $69 \%$ & $95 \%$ \\
\hline & mean anti-ln & 1.15 & 1.23 & 1.56 & 1.69 & 1.35 & 1.55 & 2.30 & 1.49 \\
\hline & $95 \% \mathrm{CI}$ & $0.65-2.03$ & $0.64-2.36$ & $0.65-3.70$ & $0.56-5.12$ & $0.56-3.27$ & $0.52-4.57$ & $0.73-7.25$ & $0.69-3.21$ \\
\hline \multirow{5}{*}{50} & mean $\ln$ & 0.16 & 0.33 & 0.80 & 0.68 & 0.24 & 0.49 & 1.33 & 0.37 \\
\hline & $\mathrm{SD} \ln$ & 0.34 & 0.45 & 0.66 & 0.53 & 0.34 & 0.50 & 0.41 & 0.50 \\
\hline & $\mathrm{CV} \% \ln$ & $211 \%$ & $135 \%$ & $82 \%$ & $78 \%$ & $140 \%$ & $102 \%$ & $31 \%$ & $133 \%$ \\
\hline & mean anti-ln & 1.17 & 1.39 & 2.23 & 1.98 & 1.27 & 1.63 & 3.80 & 1.45 \\
\hline & $95 \% \mathrm{CI}$ & $0.60-2.29$ & $0.57-3.41$ & $0.60-8.27$ & $0.68-5.70$ & $0.65-2.51$ & $0.60-4.46$ & $1.66-8.69$ & $0.54-3.92$ \\
\hline \multirow{5}{*}{100} & mean $\ln$ & 0.35 & 0.27 & 1.13 & 1.12 & 0.54 & 0.92 & 1.76 & 0.76 \\
\hline & $\mathrm{SD} \ln$ & 0.48 & 0.44 & 0.49 & 0.59 & 0.53 & 0.55 & 0.32 & 0.57 \\
\hline & $\mathrm{CV} \% \ln$ & $138 \%$ & $162 \%$ & $43 \%$ & $53 \%$ & $98 \%$ & $60 \%$ & $18 \%$ & $75 \%$ \\
\hline & mean anti-ln & 1.41 & 1.31 & 3.09 & 3.08 & 1.71 & 2.51 & 5.83 & 2.13 \\
\hline & $95 \% \mathrm{CI}$ & $0.54-3.67$ & $0.60-5.25$ & $1.16-8.20$ & $0.94-10.08$ & $0.59-4.93$ & $0.65-4.48$ & $1.20-11.65$ & $3.05-11.15$ \\
\hline \multirow{5}{*}{150} & mean ln & 0.37 & 0.75 & 1.52 & 1.17 & 0.71 & 1.11 & 1.80 & 0.98 \\
\hline & $\mathrm{SD} \ln$ & 0.39 & 0.48 & 0.46 & 0.70 & 0.36 & 0.43 & 0.45 & 0.56 \\
\hline & $\mathrm{CV} \% \ln$ & $105 \%$ & $63 \%$ & $30 \%$ & $60 \%$ & $50 \%$ & $39 \%$ & $25 \%$ & $57 \%$ \\
\hline & mean anti-ln & 1.44 & 2.12 & 4.57 & 3.21 & 2.04 & 3.05 & 6.06 & 2.67 \\
\hline & $95 \% \mathrm{CI}$ & $0.67-3.13$ & $0.82-5.49$ & $1.84-11.36$ & $0.79-13.02$ & $1.00-4.16$ & $1.29-7.21$ & $2.49-14.76$ & $0.87-8.15$ \\
\hline \multirow{5}{*}{200} & mean $\ln$ & 0,37 & 0.86 & 1.63 & 1.42 & 0.80 & 1.31 & 2.16 & 1.16 \\
\hline & $\mathrm{SD} \ln$ & 0.44 & 0.49 & 0.62 & 0.75 & 0.51 & 0.49 & 0.29 & 0.73 \\
\hline & $\mathrm{CV} \% \ln$ & $119 \%$ & $57 \%$ & $38 \%$ & $53 \%$ & $63 \%$ & $37 \%$ & $13 \%$ & $63 \%$ \\
\hline & mean anti-ln & 1.45 & 2.37 & 5.12 & 4.13 & 2.23 & 3.72 & 8.71 & 3.18 \\
\hline & $95 \% \mathrm{CI}$ & $0.60-3.52$ & $0.88-6.38$ & $1.48-17.73$ & $0.92-18.55$ & $0.81-6.16$ & $1.41-9.82$ & $4.91-15.43$ & $0.74-13.67$ \\
\hline \multirow{5}{*}{250} & mean $\ln$ & 0.58 & 0.89 & 1.70 & 1.46 & 0.79 & 1.32 & 2.31 & 1.43 \\
\hline & $\mathrm{SD} \ln$ & 0.44 & 0.56 & 0.68 & 0.90 & 0.56 & 0.64 & 0.39 & 0.59 \\
\hline & $\mathrm{CV} \% \ln$ & $75 \%$ & $63 \%$ & $40 \%$ & $62 \%$ & $71 \%$ & $49 \%$ & $17 \%$ & $41 \%$ \\
\hline & mean anti-ln & 1.79 & 2.43 & 5.50 & 4.32 & 2.21 & 3.73 & 10.02 & 4.16 \\
\hline & $95 \% \mathrm{CI}$ & $0.75-4.27$ & $0.79-7.48$ & $0.85-17.36$ & $1.41-21.37$ & $0.72-6.80$ & $1.04-13.39$ & $3.38-14.03$ & $4.62-21.75$ \\
\hline \multirow{5}{*}{300} & mean $\ln$ & 0.78 & 1.22 & 2.09 & 1.83 & 1.17 & 1.62 & 2.58 & 1.55 \\
\hline & $\mathrm{SD} \ln$ & 0.59 & 0.62 & 0.58 & 0.71 & 0.38 & 0.33 & 0.37 & 0.59 \\
\hline & $\mathrm{CV} \% \ln$ & $76 \%$ & $51 \%$ & $28 \%$ & $39 \%$ & $32 \%$ & $20 \%$ & $14 \%$ & $38 \%$ \\
\hline & mean anti-ln & 2.19 & 3.37 & 8.07 & 6.26 & 3.23 & 5.07 & 13.22 & 4.71 \\
\hline & $95 \% \mathrm{CI}$ & $0.67-7.15$ & $0.98-11.56$ & $2.55-25.52$ & $1.50-26.13$ & $1.52-6.85$ & $2.64-9.73$ & $6.27-27.86$ & $1.46-15.18$ \\
\hline
\end{tabular}

ln - natural logarithm; mean $\ln$ - ln-transformed mean number of detected eggs; SD $\ln$ - ln-transformed standard deviation of the mean; CV\% ln ln-transformed coefficient of variation; mean anti-ln - anti-ln transformed mean number of detected eggs; $95 \% \mathrm{CI}-95 \% \mathrm{confidence}$ interval for the anti-ln mean number of detected eggs.

tiplication factors presenting the relation of the number of detected eggs (y) to the number of eggs added to $1 \mathrm{~g}$ of sample ( $\mathrm{x}$ ) were calculated in the linear range of the results by conversion of linear equations $\mathrm{y}=\mathrm{ax}+\mathrm{b}$.

Multiplication factors were calculated for ln-transformed normally distributed data after their anti-ln transformation, that is for following egg contents levels: $150-300 / 1 \mathrm{~g}$ (for T. canis), 50-300/1 g (for T. ovis), 100-300/1 g (for A. suum in dog faeces) and 50-300/1 g (for $A$. suum in pig faeces).
The correlation coefficient $\left(\mathrm{R}^{2}\right)$ indicating the degree of linear relationship between the number of added parasite eggs and the number of eggs detected during the examination was calculated. Wald-Wolfowitz non-parametric statistical test was used to assess significance of statistical differences $(\mathrm{P}<0.05)$ between the results obtained in pig and dog samples enriched by $A$. suum eggs and also between results concerning the reproducibility. All statistical analysis was performed using STATISTICA 7.0 (StatSoft, Poland). 
Table 2. Parameters describing accuracy and precision for each level of Ascaris eggs contents in dog and pig faeces, for all variants of counting in McMaster method with Raynaud's modification.

\begin{tabular}{|c|c|c|c|c|c|c|c|c|c|}
\hline & & \multicolumn{4}{|c|}{ Ascaris dog faeces } & \multicolumn{4}{|c|}{ Ascaris pig faeces } \\
\hline & & one grid & two grids & $\begin{array}{l}\text { whole } \\
\text { chamber }\end{array}$ & $\begin{array}{l}\text { flotation } \\
\text { slide }\end{array}$ & one grid & two grids & $\begin{array}{l}\text { whole } \\
\text { chamber }\end{array}$ & $\begin{array}{l}\text { flotation } \\
\text { slide }\end{array}$ \\
\hline \multirow{5}{*}{15} & mean $\ln$ & 0.21 & 0.31 & 0.62 & 0.35 & 0.12 & 0.28 & 0.46 & 0.28 \\
\hline & $\mathrm{SD} \ln$ & 0.33 & 0.35 & 0.53 & 0.42 & 0.31 & 0.41 & 0.40 & 0.41 \\
\hline & $\mathrm{CV} \% \ln$ & $157 \%$ & $113 \%$ & $86 \%$ & $121 \%$ & $252 \%$ & $145 \%$ & $88 \%$ & $145 \%$ \\
\hline & mean anti-ln & 1.23 & 1.37 & 1.85 & 1.41 & 1.13 & 1.33 & 1.58 & 1.33 \\
\hline & $95 \% \mathrm{CI}$ & $0.64-2.36$ & $0.67-2.77$ & $0.64-5.33$ & $0.61-3.28$ & $0.61-2.12$ & $0.58-3.02$ & $0.71-3.52$ & $0.58-3.02$ \\
\hline \multirow{5}{*}{25} & mean $\ln$ & 0.23 & 0.51 & 0.85 & 0.49 & 0.37 & 0.54 & 0.86 & 0.45 \\
\hline & $\mathrm{SD} \ln$ & 0.37 & 0.42 & 0.49 & 0.45 & 0.44 & 0.51 & 0.62 & 0.52 \\
\hline & $\mathrm{CV} \% \ln$ & $161 \%$ & $82 \%$ & $58 \%$ & $92 \%$ & $119 \%$ & $96 \%$ & $72 \%$ & $116 \%$ \\
\hline & mean anti-ln & 1.26 & 1.66 & 2.33 & 1.63 & 1.45 & 1.71 & 2.36 & 1.56 \\
\hline & $95 \% \mathrm{CI}$ & $0.60-2.62$ & $0.72-3.82$ & $0.87-6.22$ & $0.67-4.01$ & $0.60-3.52$ & $0.61-4.77$ & $0.69-8.09$ & $0.56-4.40$ \\
\hline \multirow{5}{*}{50} & mean ln & 0.39 & 0.64 & 1.11 & 0.74 & 0.44 & 0.75 & 1.23 & 0.80 \\
\hline & $S D \ln$ & 0.41 & 0.53 & 0.50 & 0.51 & 0.44 & 0.48 & 0.41 & 0.56 \\
\hline & $\mathrm{CV} \% \ln$ & $107 \%$ & $84 \%$ & $45 \%$ & $70 \%$ & $100 \%$ & $65 \%$ & $34 \%$ & $70 \%$ \\
\hline & mean anti-ln & 1.47 & 1.89 & 3.04 & 2.09 & 1.55 & 2.11 & 3.40 & 2.22 \\
\hline & $95 \% \mathrm{CI}$ & $0.64-3.37$ & $0.65-5.48$ & $1.12-8.24$ & $0.75-5.82$ & $0.64-3.72$ & $0.80-5.55$ & $1.49-7.81$ & $0.72-6.80$ \\
\hline \multirow{5}{*}{100} & mean $\ln$ & 0.66 & 1.08 & 1.69 & 1.07 & 0.53 & 0.94 & 1.64 & 1.07 \\
\hline & $\mathrm{SD} \ln$ & 0.49 & 0.49 & 0.47 & 0.50 & 0.43 & 0.45 & 0.38 & 0.65 \\
\hline & $\mathrm{CV} \% \ln$ & $75 \%$ & $45 \%$ & $28 \%$ & $46 \%$ & $81 \%$ & $48 \%$ & $23 \%$ & $61 \%$ \\
\hline & mean anti-ln & 1.93 & 2.94 & 5.40 & 2.92 & 1.70 & 2.56 & 5.13 & 2.91 \\
\hline & $95 \% \mathrm{CI}$ & $0.72-5.17$ & $1.11-7.78$ & $2.10-13.88$ & $1.08-7.92$ & $0.72-4.01$ & $1.04-6.30$ & $2.40-10.96$ & $0.80-10.61$ \\
\hline \multirow{5}{*}{150} & mean $\ln$ & 0.67 & 1.14 & 1.93 & 1.37 & 0.96 & 1.30 & 1.94 & 1.41 \\
\hline & $\mathrm{SD} \ln$ & 0.51 & 0.56 & 0.44 & 0.73 & 0.44 & 0.61 & 0.56 & 0.54 \\
\hline & $\mathrm{CV} \% \ln$ & $75 \%$ & $49 \%$ & $23 \%$ & $53 \%$ & $46 \%$ & $47 \%$ & $29 \%$ & $38 \%$ \\
\hline & mean anti-ln & 1.96 & 3.14 & 6.89 & 3.95 & 2.62 & 3.68 & 6.93 & 4.11 \\
\hline & $95 \% \mathrm{CI}$ & $0.71-5.39$ & $1.02-9.66$ & $2.84-16.73$ & $0.92-16.98$ & $1.08-6.35$ & $1.09-12.37$ & $2.28-21.05$ & $1.40-12.07$ \\
\hline \multirow{5}{*}{200} & mean $\ln$ & 0.79 & 1.29 & 2.29 & 1.59 & 1.07 & 1.35 & 2.32 & 1.74 \\
\hline & $\mathrm{SD} \ln$ & 0.55 & 0.54 & 0.23 & 0.47 & 0.44 & 0.57 & 0.15 & 0.50 \\
\hline & $\mathrm{CV} \% \ln$ & $69 \%$ & $42 \%$ & $10 \%$ & $29 \%$ & $41 \%$ & $43 \%$ & $6 \%$ & $29 \%$ \\
\hline & mean anti-ln & 2.19 & 3.62 & 9.85 & 4.93 & 2.92 & 3.85 & 10.15 & 5.68 \\
\hline & $95 \% \mathrm{CI}$ & $0.74-6.53$ & $1.23-10.66$ & $6.21-15.62$ & $1.93-12.55$ & $1.21-7.02$ & $1.22-12.14$ & $7.58-13.58$ & $2.11-15.28$ \\
\hline \multirow{5}{*}{250} & mean $\ln$ & 1.04 & 1.52 & 2.37 & 1.95 & 1.13 & 1.66 & 2.61 & 1.84 \\
\hline & $\mathrm{SD} \ln$ & 0.57 & 0.52 & 0.38 & 0.63 & 0.53 & 0.50 & 0.21 & 0.50 \\
\hline & $\mathrm{CV} \% \ln$ & $55 \%$ & $34 \%$ & $16 \%$ & $32 \%$ & $47 \%$ & $30 \%$ & $8 \%$ & $27 \%$ \\
\hline & mean anti-ln & 2.82 & 4.55 & 10.66 & 7.00 & 3.11 & 5.27 & 13.58 & 6.28 \\
\hline & $95 \% \mathrm{CI}$ & $0.90-8.86$ & $1.61-12.82$ & $2.84-15.66$ & $4.94-23.00$ & $1.07-9.05$ & $1.92-14.45$ & $8.97-20.55$ & $2.31-17.07$ \\
\hline \multirow{5}{*}{300} & mean $\ln$ & 1.28 & 1.87 & 2.73 & 2.07 & 0.96 & 1.68 & 2.68 & 2.03 \\
\hline & $\mathrm{SD} \ln$ & 0.67 & 0.66 & 0.36 & 0.65 & 0.71 & 0.56 & 0.32 & 0.50 \\
\hline & $\mathrm{CV} \% \ln$ & $52 \%$ & $35 \%$ & $13 \%$ & $31 \%$ & $74 \%$ & $33 \%$ & $12 \%$ & $25 \%$ \\
\hline & mean anti-ln & 3.58 & 6.50 & 15.37 & 7.90 & 2.62 & 5.36 & 14.64 & 7.64 \\
\hline & $95 \% \mathrm{CI}$ & $0.90-8.86$ & $1.61-12.82$ & $4.94-23.00$ & $1.98-24.73$ & $0.63-10.89$ & $1.75-16.44$ & $7.78-27.54$ & $2.81-20.80$ \\
\hline
\end{tabular}

ln - natural logarithm; mean $\ln$ - ln-transformed mean number of detected eggs; SD $\ln$ - ln-transformed standard deviation of the mean; CV\% $1 n$ ln-transformed coefficient of variation; mean anti-ln - anti-ln transformed mean number of detected eggs; $95 \% \mathrm{CI}-95 \%$ confidence interval for the anti-ln mean number of detected eggs.

\section{RESULTS}

Results were compared separately for each part of the McMaster chamber and flotation slide (flotation in the tube variant) for Toxocara canis, Trichuris ovis and $A s$ caris suum eggs (the last of the species served as a control). All results were presented with reference to $1 \mathrm{~g}$ of faeces. Data obtained were not normally distributed and did not follow Poisson distribution. In order to present normally distributed data, the values obtained were transformed using natural logarithm. However, data at low lev- els of egg content were not normally distributed even if ln-transformed. Normally distributed data were obtained only for the following content levels: 150-300 eggs/g (for T. canis), 50-300 eggs/g (for T. ovis), 100-300 eggs/g (for A. suum in dog faeces) and 50-300 eggs/g (for A. suum in pig faeces).

\section{Mean numbers of detected eggs}

The mean numbers of detected eggs showed the accuracy of the method. As shown in Tables 1 and 2, the highest mean numbers of detected eggs were obtained 
for A. suum, slightly lower for T. ovis and the lowest for T. canis (and they were almost half lower than that for A. suum).

The values of the mean number of eggs counted in the McMaster chamber increased in the following order: one grid, two grids and the whole chamber. These results were presented in a different way in tube flotation: the highest values were obtained for A. suum eggs, slightly lower for T. canis and the lowest for T. ovis eggs. In the case of T. canis and A. suum, mean numbers of detected eggs obtained in flotation slide variant were lower than those for the whole chamber and higher than those in one grid and two grids variants. However, these results in flotation in the tube were lower than for the whole chamber and comparable to two grids variant for $T$. ovis eggs. High values of $95 \%$ confidence intervals obtained for the mean number of detected eggs showed a low accuracy of results.

\section{Coefficients of variation}

The coefficients of variation (CV\%; see Tables 1,2$)$ showed the precision of the method. The coefficients of variation $(\mathrm{CV} \%)$ concerning numbers of detected eggs showed a general trend to decrease together the increasing number of eggs enriching the sample. At the lower levels of egg content, CV\% was high and often exceeded $100 \%$. Among all variants of the counting methods the best repeatability of the results (the lowest coefficients of variation) for all types of parasitic eggs was obtained with the use of the whole chamber variant. In the case of flotation in the tube $\mathrm{CV} \%$ was comparable with that obtained in two grids variant, with the exception of T. ovis eggs. In the tube flotation variant the highest value of $\mathrm{CV} \%$ was obtained for T. ovis, whereas in the McMaster chamber for $T$. canis eggs.

\section{Correlation coefficients}

Correlation coefficients between the number of added and detected eggs of T. canis, T. ovis and A. suum $\left(\mathrm{R}^{2}\right)$ showed the linear range of the results (Fig. 2). The coefficients were calculated for ln-transformed normally distributed data after their anti-ln transformation. $\mathrm{R}^{2}$ was calculated for results derived by examined samples with the following egg contents levels: 150-300/1 (for T. canis), 50-300/g (for T. ovis), 100-300/g (for A. suum in dog faeces) and 50-300/g (for $A$. suum in pig faeces).

\section{Multiplication factors}

Multiplication factor for estimation of the real number of eggs in $1 \mathrm{~g}$ of faeces was calculated from the transformed equations illustrating relationships between the number of parasite eggs detected and that of the eggs added. The values of multiplication factor, counted in the whole chamber variant, were the highest for T. canis (46) and lower for T. ovis (28); for A. suis, the factor was identical (21) both for dog and pig faeces.

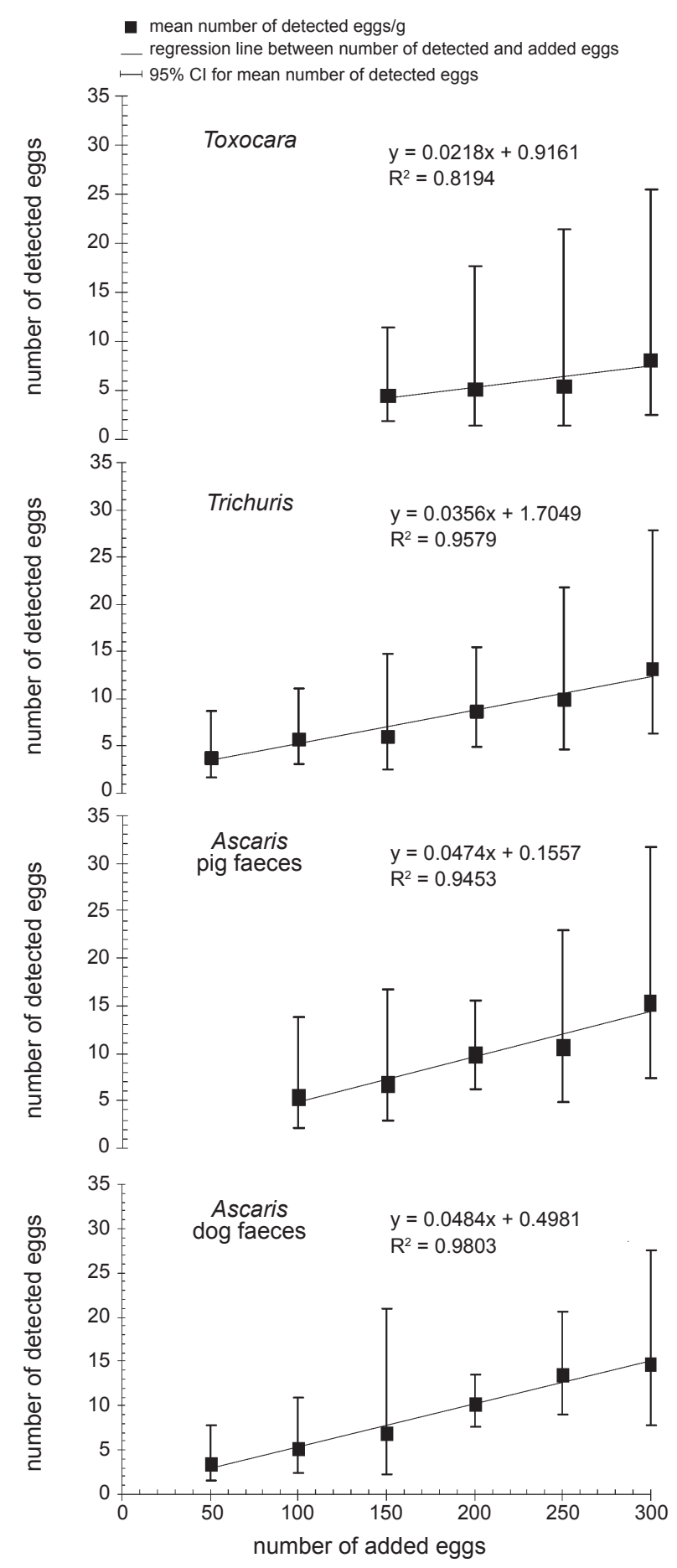

Fig. 2. Estimation of the linear range of the results obtained by McMaster method in Raynaud's modification..

\section{Percentages of positive results}

Percentages of positive results obtained in different variants of the method are shown in Table 3. In all variants of counting in the McMaster chamber the highest percentage of positive results was obtained for $A$. suum eggs, slightly lower for $T$. ovis, and the lowest for $T$. canis eggs. In the flotation slide variant the number of positive 
Table 3. The percentage of positive results for each level of parasite eggs contents, for all variants of counting in McMaster method in Raynaud's modification.

\begin{tabular}{|c|c|c|c|c|c|c|c|c|c|}
\hline \multirow{2}{*}{\multicolumn{2}{|c|}{ Variants of the method }} & \multicolumn{8}{|c|}{ Number of added eggs per $1 \mathrm{~g}$ of sample } \\
\hline & & 15 & 25 & 50 & 100 & 150 & 200 & 250 & 300 \\
\hline & & \multicolumn{8}{|c|}{$\%$ of positive results } \\
\hline \multirow{4}{*}{$\begin{array}{l}\text { Toxocara } \\
\text { canis } \\
\text { dog faeces }\end{array}$} & one grid & 10 & 20 & 15 & 30 & 50 & 45 & 75 & 70 \\
\hline & two grids & 20 & 30 & 40 & 60 & 80 & 85 & 80 & 90 \\
\hline & whole chamber & 30 & 55 & 65 & 95 & 100 & 95 & 95 & 100 \\
\hline & flotation slide & 15 & 50 & 70 & 90 & 85 & 90 & 90 & 95 \\
\hline \multirow{4}{*}{$\begin{array}{l}\text { Trichuris } \\
\text { suis } \\
\text { dog faeces }\end{array}$} & one grid & 25 & 35 & 40 & 55 & 85 & 80 & 85 & 100 \\
\hline & two grids & 40 & 45 & 55 & 80 & 80 & 95 & 90 & 100 \\
\hline & whole chamber & 70 & 75 & 100 & 100 & 100 & 100 & 100 & 100 \\
\hline & flotation slide & 45 & 55 & 40 & 75 & 85 & 80 & 100 & 100 \\
\hline \multirow{4}{*}{$\begin{array}{l}\text { Ascaris } \\
\text { suum } \\
\text { dog faeces }\end{array}$} & one grid & 30 & 30 & 35 & 65 & 70 & 85 & 85 & 75 \\
\hline & two grids & 45 & 65 & 55 & 95 & 90 & 90 & 100 & 90 \\
\hline & whole chamber & 70 & 85 & 95 & 100 & 100 & 100 & 100 & 100 \\
\hline & flotation slide & 45 & 60 & 75 & 95 & 85 & 100 & 100 & 100 \\
\hline \multirow{4}{*}{$\begin{array}{l}\text { Ascaris } \\
\text { suum } \\
\text { pig faeces }\end{array}$} & one grid & 15 & 40 & 50 & 65 & 90 & 90 & 90 & 90 \\
\hline & two grids & 35 & 60 & 80 & 90 & 90 & 90 & 90 & 100 \\
\hline & whole chamber & 60 & 75 & 100 & 100 & 100 & 100 & 100 & 100 \\
\hline & flotation slide & 35 & 50 & 75 & 85 & 95 & 100 & 100 & 100 \\
\hline
\end{tabular}

results was similar for all types of nematodes. These values represen the limits of detection (Table 4). The highest limit of detection in all variants of the chamber was obtained for T. canis eggs (from 25 to $250 \mathrm{eggs} / \mathrm{g}$ ) - about twice as high as that for T. ovis and A. suum (from 15 to 100 eggs/g). The lowest limit of detection for flotation in the tube was obtained for T. ovis (four times higher than results obtained for other parasite species).

\section{Sensitivity}

Sensitivity of individual variants of the method estimated from the results obtained in samples with egg contents above the limits of detection (see Table 4) is presented in Table 5. Sensitivity of the McMaster chamber variants increased in following order: one grid, two grids and the whole chamber. Sensitivity of the flotation in the tube variant was lower than in the whole chamber. Comparison of the results obtained for individual parasites indicated the lowest sensitivity with $T$. canis eggs.

\section{Comparison pig and dog faeces}

Comparison of samples of pig and dog faeces enriched by $A$. suum eggs did not show differences in any variant because average numbers of detected eggs per $1 \mathrm{~g}$ of faeces, 95\% confidence intervals for means, standard deviations and coefficients of variation did not differ significantly. Quality parameters such as limit of detection, sensitivity and percentage of positive results for particular variants of the method used were also similar. Moreover, calculated multiplication factors for one grid and two grids variants were similar to the multiplication factors described in the original McMaster method with Raynaud's modification.
Table 4. Limit of detection (number of parasite eggs per $1 \mathrm{~g}$ of the sample) for all variants of counting in McMaster method in Raynaud's modification.

\begin{tabular}{lcccc}
\hline Variants of the method & $\begin{array}{c}\text { Dog faeces } \\
\text { Toxocara }\end{array}$ & Trichuris & Ascaris & $\begin{array}{c}\text { Pig faeces } \\
\text { Ascaris }\end{array}$ \\
\hline One gird & 250 & 100 & 100 & 50 \\
Two grids & 100 & 50 & 25 & 25 \\
Whole chamber & 25 & 15 & 15 & 15 \\
Flotation slide & 25 & 100 & 25 & 25 \\
\hline
\end{tabular}

Table 5. Sensitivity (\%) for all variants of the McMaster method in Raynaud's modification.

\begin{tabular}{|c|c|c|c|c|}
\hline \multirow[t]{2}{*}{ Variants of the method } & \multicolumn{3}{|c|}{ Dog faeces } & \multirow{2}{*}{$\begin{array}{c}\text { Pig faeces } \\
\text { Ascaris }\end{array}$} \\
\hline & Toxocara & Trichuris & Ascaris & \\
\hline One grid & 85.00 & 88.75 & 85.00 & 80.00 \\
\hline Two grids & 86.25 & 94.00 & 90.83 & 90.83 \\
\hline Whole chamber & 91.66 & 96.43 & 96.43 & 97.14 \\
\hline Flotation slide & 85.00 & 91.25 & 92.50 & 90.83 \\
\hline
\end{tabular}

\section{Reproducibility}

Values of reproducibility (degree of agreement between results obtained independently by two persons) are summarized in Table 6. Results were compared by the Wald-Wolfowitz test $(\mathrm{P}<0.05)$ and provided no statistical significant differences in any variant.

\section{DISCUSSION}

Most of publications on the accuracy and precision of detection of parasite eggs were based on samples of faeces from naturally or experimentally infected animals. For that reason the real number of eggs in faeces could not be properly assessed (Ward et al. 1997, Ojeda-Robertos et al. 2007, Pereckiene et al. 2007, Daş et al. 2011). Therefore, samples were enriched with a known number of parasite eggs in the present study to obtain results as reliable as possible. Vadlejch et al. (2011) compared the accuracy and precision of various modifications of McMaster method for sheep faeces enriched by eggs of the nematode Teladorsagia circumcincta (Stadelmann, 1894).

However, these authors did not carry out a multiplication factor analysis to calculate the real content of eggs per $1 \mathrm{~g}$ of faeces. A study by Karamon et al. (2010) on the limit of detection of tapeworms Echinococcus multilocularis Leuckart, 1863 in faeces by sedimentation method (SCT) was also based on the enriched samples. In the present study, the use of samples enriched with a known number of parasite eggs allowed for a full analysis of the actual accuracy and precision of the McMaster method modified by Raynaud (1970).

The results of the present experiments indicate that values of the number of parasite eggs detected in dog faeces using McMaster method with Raynaud's modification differed from those reported in the original description of this modification (Raynaud 1970). In addition, signifi- 
Table 6. Test of reproducibility of examination of dog faecal samples enriched with 100 eggs of Ascaris suum per $1 \mathrm{~g}$ of faeces comparison of results obtained independently by two persons.

\begin{tabular}{|c|c|c|c|c|c|c|c|c|c|}
\hline & & \multicolumn{4}{|l|}{ Investigator I } & \multicolumn{4}{|c|}{ Investigator II } \\
\hline & & one grid & two grids & $\begin{array}{l}\text { whole } \\
\text { chamber }\end{array}$ & $\begin{array}{l}\text { flotation } \\
\text { slide }\end{array}$ & one grid & two grids & $\begin{array}{l}\text { whole } \\
\text { chamber }\end{array}$ & $\begin{array}{l}\text { flotation } \\
\text { slide }\end{array}$ \\
\hline \multirow{5}{*}{ Toxocara } & mean $\ln$ & 0.35 & 0.27 & 1.13 & 1.12 & 0.35 & 0.58 & 1.13 & 1.12 \\
\hline & $\mathrm{SD} \ln$ & 0.48 & 0.44 & 0.49 & 0.59 & 0.48 & 0.54 & 0.49 & 0.59 \\
\hline & $\mathrm{CV} \% \ln$ & $138 \%$ & $162 \%$ & $43 \%$ & $53 \%$ & $138 \%$ & $94 \%$ & $43 \%$ & $53 \%$ \\
\hline & mean anti-ln & 1.41 & 1.31 & 3.09 & 3.08 & 1.41 & 1.78 & 3.09 & 3.08 \\
\hline & $95 \%$ CI & $0.54-3.67$ & $0.60-5.25$ & $1.16-8.20$ & $0.94-10.08$ & $0.54-3.67$ & $0.60-5.25$ & $1.16-8.20$ & $0.94-10.08$ \\
\hline \multirow{5}{*}{ Trichuris } & mean $\ln$ & 0.54 & 0.92 & 1.76 & 0.76 & 0.54 & 0.92 & 1.76 & 0.76 \\
\hline & $\mathrm{SD} \ln$ & 0.53 & 0.55 & 0.32 & 0.57 & 0.53 & 0.55 & 0.32 & 0.57 \\
\hline & $\mathrm{CV} \% \ln$ & $98 \%$ & $60 \%$ & $18 \%$ & $75 \%$ & $98 \%$ & $60 \%$ & $18 \%$ & $75 \%$ \\
\hline & mean anti-ln & 1.71 & 2.51 & 5.83 & 2.13 & 1.71 & 2.51 & 5.83 & 2.13 \\
\hline & $95 \%$ CI & $0.59-4.93$ & $0.65-4.48$ & $1.20-11.65$ & $3.05-11.15$ & $0.59-4.93$ & $0.83-7.57$ & $3.05-11.15$ & $0.68-6.68$ \\
\hline
\end{tabular}

ln - natural logarithm; mean $\ln$ - ln-transformed mean number of detected eggs; SD $\ln$ - ln-transformed standard deviation of the mean; CV\% ln ln-transformed coefficient of variation; mean anti-ln - anti-ln transformed mean number of detected eggs; $95 \% \mathrm{CI}-95 \%$ confidence interval for the anti-ln mean number of detected eggs.

cant differences were observed in the accuracy and precision of the method depending on the type of parasite eggs. In the case of Toxocara canis eggs examined in the McMaster chamber, significantly lower numbers of eggs were detected in $1 \mathrm{~g}$ of faeces than in the case of Trichuris ovis and Ascaris suum. It is most likely that low detection T. canis eggs in the McMaster chamber was caused by the specific shell structure of these eggs with strong adhesive properties (Overgaauw and Knapen 2008), which could result in a higher loss of parasite eggs during their handling.

The flotation tube variant was characterised by the lowest number of detected eggs of Trichuris. It is highly probable that it was related to the high specific gravity of this type of eggs that affected longer and less effective flotation process in the high column of saturated solution. According to our study the level of detection of Toxocara eggs in the McMaster chamber was twice lower than assumed by Raynaud (1970). However, for Ascaris eggs, both in pig and dog faeces, detection was close to the assumptions of McMaster method in Raynaud's modification. Detection of all three types parasite eggs as a result of the tube flotation is several times lower than the assumptions of Raynaud's modification. Cringoli et al. (2011) also confirmed better detection of the eggs of the hookworm Ancylostoma caninum (Ercolani, 1859) with the use of McMaster chamber than in a test tube.

According to the method applied, the number of eggs in one gram of faeces is influenced by correctness of the multiplication factor inferred from the particular part of the McMaster chamber or to flotation slide. According to Raynaud's (1970) modification, multiplication factors to estimate the number of parasite eggs in $1 \mathrm{~g}$ of faeces are: 100 for one grid, 50 for two grids, 15 for the whole McMaster chamber and 7 for flotation slide. It should be emphasized that multiplication factors in most of the McMaster method's modifications are estimated mainly from calculation of the proportion of the sample dilution ratio and the volume of the individual part of the McMaster chamber (MAFF 1986, Cringoli et al. 2004, Vadlejch et al. 2011).

This method of calculation is based on the assumption that all the eggs of parasites present in the sample are detected. However, results of our study has demonstrated that such direct mathematical conversion may not correspond to reality and that the multiplication factors may vary significantly between different types of parasite eggs. Multiplication factors to estimate the real number of parasite eggs in $1 \mathrm{~g}$ of faeces should be calculated based on the number of eggs detected by McMaster method in the samples containing known number of eggs. The present study has also shown that the calculation of parasite eggs from the whole McMaster chamber provides the most accurate estimates of the number of parasite eggs per unit mass of faeces. Using this approach, the multiplication factors of 46 were obtained for T. canis eggs, 28 for $T$. ovis and 21 for A. suum. This method appeared to provide the highest sensitivity and the lowest limit of detection.

Our results were not normally distributed (even after ln-transformation) at low levels of parasite eggs contents, which indicates showed a high dispersion of values obtained. Therefore, correct quantitative data are difficult to be obtained with the use of McMaster method in Raynaud's modification at low levels of parasite egg contents. Moreover, our study has revealed that quantitative examination in smaller areas of the McMaster chamber (one grid or two grids) and on the flotation slide (even at higher levels of parasite eggs contents) may not ensure that correct quantitative calculation are made.

The multiplication factors for the McMaster chamber calculated on the basis of our study reached by far the highest value the eggs of $T$. canis, whereas those for A. suum eggs in the McMaster chamber roughly corresponded to the parameters provided by Raunaud (1970). 
In addition, multiplication factors calculated by Raynaud (1970) would be correct only if worm eggs are distributed regularly in the chamber, which is normally the case as observed by Rinaldi et al. (2011) and also in the present study (the eggs of all nematode species used tended to accumulate in the central part of the McMaster chamber - in the grids).

There are several factors influencing the results of examination of faeces, such as the McMaster chamber construction (chambers are available in various sizes and volumes) and the weight ratio of liquid samples for flotation and flotation density of the fluid. Pereckiene et al. (2010) compared the detection of eggs of parasitic nematodes with two types of McMaster chambers (volume of $0.3 \mathrm{ml}$ and $1.5 \mathrm{ml}$ ) and a much better detection was achieved using the larger chamber. An important factor is also the ratio of the weight of faecal samples to the volume of flotation solution (Cringoli et al. 2004, Pereckiene et al. 2007). Ratio of 1 : 14, which was used in the McMaster method modified by Raynaud (1970), is characterized by the highest efficiency (Vadlejch et al. 2011). Effect of flotation solution density (Cringoli et al. 2004) used in this study, which is a saturated solution of magnesium sulphate $\left(\mathrm{MgSO}_{4}\right)$ (specific gravity 1.28 ), exceeds the specific gravity of the eggs of parasites and is suitable for flotation of eggs of Toxocara (specific gravity 1.10), Ascaris (specific gravity 1.13) and Trichuris (specific gravity 1.15). A saturated solution of magnesium sulphate does not damage the eggs of parasites of these species caused by osmotic pressure of flotation fluid.

Comparison of samples of dog and pig faeces did not show significant differences in detection of nematode eggs in the present study, but the type of faeces may have a significant impact on the results of parasitological research made with flotation methods. For example, diarrhoeal faeces of suckling piglets contained a lot of fat fraction flowing to the surface of flotation liquid, which reduces significantly the visibility in the McMaster chamber during microscopic examination (Karamon et al. 2008). In this case, the efficiency of detection can be increased by the use of centrifugation with Percoll.

Currently, new development of the McMaster method is the FLOTAC apparatus (Cringoli et al. 2010). The detection of parasite eggs was increased by using two chambers of this apparatus with a total volume of $10 \mathrm{ml}$ and double centrifugation, but the real limit of detection of FLOTAC method is yet to be determined.

The present study has demonstrated that it is important to validate the method before its use in routine diagnostics because some differences between theoretical assumptions and real results may appear. Adequate knowledge of method parameters, which influences correct interpretation of data obtained, is also required by laws regulating the work of diagnostic laboratories. For example, ISO/ IEC 17025:2005 standard and related documents require that only validated methods should be used by accredited laboratories.

It should be stressed that the validation of any coproscopic method is very difficult. This is mainly due to the lack of linearity at the lowest levels of parasite eggs content. At these levels, the risk of serious errors is rather high. Another major problem is the heterogeneity of matrices (faeces) and eggs of the parasite. So, it seems to be impossible to use one universal multiplication factor to all types of examined samples and all types of parasite eggs. Therefore, it is recommended to validate methods to be used with samples containing the known number of parasites.

Our study does not provide the description of the method ready to use for practicing laboratory workers, but represents an attempt to find the proper way for confirmation of real accuracy and precision of the selected quantitative coproscopic method. We hope that our findings will be useful for parasitologists working in diagnostic laboratories and will help in preparation of the universal rules concerning validation of parasitological quantitative methods.

\section{REFERENCES}

Cringoli G., Rinaldi L., Maurelli M.P., Morgoglione M.E., Musella V., Utzinger J. 2011: Ancylostoma caninum: calibration and comparison of diagnostic accuracy of flotation in tube, McMaster and FLOTAC in fecal samples of dogs. Exp. Parasitol. 128: 32-37.

Cringoli G., Rinaldi L., Maurelli M.P., Utzinger J. 2010: FLOTAC: new multivalent techniques for qualitative and quantitative copromicroscopic diagnosis of parasites in animals and humans. Nat. Protoc. 5: 503-515.

Cringoli G., Rinaldi L., Veneziano V., Capelli G., Scala A. 2004: The influence of flotation solution, sample dilution and the choice of McMaster slide area (volume) on the reliability of the McMaster technique in estimating the faecal egg counts of gastrointestinal strongyles and Dicrocoelium dendriticum in sheep. Vet. Parasitol. 123: 121-131.
Daş G., Savaş T., Kaufmann F., Idris A., Abel H., Gauly M. 2011: Precision repeatability and representative ability of faecal egg counts in Heterakis gallinarum infected chickens. Vet. Parasitol. 183: 87-94.

Fülleborn F. 1921: Über die Wanderung von Ascaris und Nematodenlarven im Körper und intrauterine Ascarisinfektion. Arch. Schiffs- u. Tropenhyg. 25: 146-149.

Gordon H., Whitlock H. 1939: A new technique for counting nematode eggs in sheep faeces. J. Sci. Ind. Res. 12: 50-52.

ISO/IEC 17025:2005: General requirements for the competence of testing and calibration laboratories. ISO copyright office, Geneva, Switzerland, $14 \mathrm{pp}$.

ISO 16140:2003: Microbiology of food and animal feeding stuffs. Protocol for the validation of alternative methods. European Committee for Standardization, Brussels, Belgium, 11 pp. 
Karamon J., Sroka J., Cencek T. 2010: Limit of detection of sedimentation and counting technique (SCT) for Echinococcus multilocularis diagnosis, estimated under experimental conditions. Exp. Parasitol. 124: 244-246.

Karamon J., Ziomko I., Cencek T., Sroka J. 2008: Modified flotation method with the use of Percoll for the detection of Isospora suis oocysts in suckling piglet faeces. Vet. Parasitol. 156: 324-328.

Levecke B., De Wilde N., Vandenhoute E., Vercruysse J. 2009: Field validity and feasibility of four techniques for the detection of Trichuris in simians: a model for monitoring drug efficacy in public health? PLoS Negl. Trop. Dis. 3: e366.

LOMBARD B. 2006: Estimation of measurement uncertainty in food microbiology: the ISO approach. Accred. Qual. Assur. 11: 94-100.

MAFF (Ministry of Agriculture, Fisheries and Food) 1986: Manual of Veterinary Parasitological Techniques. HMSO, London, $24 \mathrm{pp}$.

Ojeda-Robertos N.F., Torres-Acosta J.F.J., Ayala-Burgos A., Aguilar-Caballero A.J., Cob-Galera L.A., Mendoza-deGives P. 2008: A technique for quantification of Duddingtonia flagrans chlamydospores in sheep faeces. Vet. Parasitol. 152: 339-343.

Overganuw P.A.M., van Knapen F. 2008: Toxocarosis, an important zoonosis. Eur. J. Comp. Anim. Pract. 18: 259-266.

Pereckiene A., Kaziūnaite V., Vyšniauskas A., Petkevičius S., Malakaskas A., Šarkūnas M., Taylor M.A. 2007: A comparison of modifications of the McMaster method for the

Received 31 May 2012 enumeration of Ascaris sum eggs in pig faecal samples. Vet. Parasitol. 149: 111-116.

RaYNAUd J.P. 1970: Etude de l'efficacité d'une technique de coproscopie quantitative pour le diagnostic de routine et le controle des infestations parasitaires des bovins, ovins, equines et porcins. Ann. Parasitol. (Paris) 45: 321-342.

Rinaldi L., Coles G., Maurelli M.P., Cringoli G. 2011: Calibration and diagnostic accuracy of simple flotation, McMaster and FLOTAC for parasite egg counts in sheep. Vet. Parasitol. 177: 345-352.

Rossangio C.E., Gruner L. 1990: Accuracy of two methods for counting eggs of sheep nematode parasites. Vet. Parasitol. 39: $115-121$.

Turkson P.K., Ahafia K.K. 1994: A comparison of modified McMaster and Brumpt's methods in assessment of nematode egg output in an N'dama cattle herd. Acta Trop. 57: 341-344.

Utzinger J., Laura R., Lohourignon L.K., Rohner F., Zimmermann M.B., Tschannen A.B., N'Goran K.N., Cringoli G. 2008: FLOTAC: a new sensitive technique for the diagnosis of hookworm infections in humans. Trans R. Soc. Trop. Med. Hyg. 102: 84-90.

Vadlejch J., Petrtýl M., Zaichenko I., Čadková Z., Jankovská I., Langrová I., Moravec M. 2011: Which McMaster egg counting technique is the most reliable? Parasitol. Res. 109: $1387-1394$.

Ward M.P., Lyndal-Murphy M., Baldock F.C. 1997: Evaluation of a composite method for counting helminth eggs in cattle faeces. Vet. Parasitol. 73: 181-187.

Accepted 4 February 2013 